\section{Interpolation of Perceived Compliance and Behavior Modification in Adolescents Undergoing Treatment with Fixed Orthodontic Appliances: A Prospective Study}

\section{Abstract}

Aim: The purpose of this study was to monitor the impact of fixed orthodontic appliances on the patient's daily life activities and evaluate the influence of information given to the patient prior to treatment and to review different studies in relevance to the field.

Objective: To assess the impact of orthodontic treatment with fixed appliances on the daily life activities of adolescents.

Patients and methods: This study was conducted in the department of orthodontics at Karolinska institute, Huddinge, Stockholm. The study group comprised of 20 adolescent patients, from both sexes who were treated with fixed orthodontic appliances. Specific self-administered log-books covering aspects of pain sensation, oral hygiene, eating habits, sleep, speech and social activities. Data were collected, coded and analyzed by descriptive statistics.

Results: For the pain experience it was documented that $80 \%$ could manage to continue the treatment without pain by the end of the first week, while $20 \%$ were still having mild to moderate pain (=2-6 on the VAS), except in one patient who experienced severe pain ( $=9$ on VAS) during the $5^{\text {th }}$ week. Cheek and tongue ulcerations were reported by $50 \%$ of participants on the $1^{\text {st }}$ day of the treatment, and that number has reduced to reach $35 \%$ by the end of the follow up period ( $=8$ weeks). Only one patient considered terminating treatment due to pain, and his treatment was terminated after $2^{\text {nd }}$ stage of the study.

Conclusion: The impact of orthodontic treatment with fixed appliances on the daily life activities of adolescents are expected to occur, mainly during the first week of treatment, primarily because of pain and discomfort. Those impacts can be controlled and managed by good communication between patient and doctor. Adding the social and speech impacts part in the treatment consent could be recommended.

Keywords: Fixed appliances; Pain management; Psychosocial life; Communication skills; Adolescents

\section{Abdullah Obaid Alanazi ${ }^{1}$, Jan Huggare ${ }^{2}$, Khurram Latif Shah ${ }^{3 *}$ and Khadar Vali Shaik ${ }^{3}$}

1 Department of Orthodontics \& Craniofacial Orthopeadics, Director Specialized Dental Center, Al-Qurayyat Health Affairs, Saudi Arabia

2 Department of Orthodontics, Karolinska Institute, Sweden

3 Gurayat General Hospital/ Specialized Dental Center, Al-Qurayyat Health Affairs, Saudi Arabia

\section{*Corresponding author: Khurram Latif Shah \\ ” klshah@moh.gov.sa}

Oral and Maxillofacial Surgeon/ Head of Division, Gurayat General Hospital/ Specialized Dental Center, Al-Qurayyat Health Affairs, Saudi Arabia.

Citation: Alanazi AO, Huggare J, Shah KL, Shaik KV (2018) Interpolation of Perceived Compliance and Behavior Modification in Adolescents Undergoing Treatment with Fixed Orthodontic Appliances: A Prospective Study. J Orthod Endod Vol.4 No.3:11

\section{Introduction}

Since maintenance of the quality of life of the orthodontic patients has become an integral role of orthodontists, several studies have been conducted in this regard, focusing on changes in the daily life activities during active treatment. Pain will be at its maximum during the first week of treatment and the main reason compromising the quality of life. Patients undergoing orthodontic treatment are likely to report an oral health impact, which may suggest that the treatment affects the patient's quality of life. It was also found that, at one week after the installation of fixed appliances, the quality of life was at worst because of 
combination of physical pain, psychological discomfort, and physical disability [1]. It was also reported that $90 \%$ of patients complain pain during the first day, which declined gradually over the following 7-9 days [2] and found that $95 \%$ of patients reported pain after 24 hours and $25 \%$ after 1 week [3]. Duration of pain will range from 24 hours to 14 days, although longer duration of pain was reported by $30 \%$ of patients. Teeth will be the main sites of pain, in addition to the soft tissues (Cheeks and gums) as reported by $30 \%$ of the patients [4]. No matter how much progress has been made in orthodontics or how competent the practitioner is; orthodontic treatment is still associated with discomfort and pain after initial arch wire placement starts after 3 hours and peaks at 19 hours followed by gradual decrease to preoperative values by day 7 . The highest average visual analogue scale (VAS) scores will range to below average values, indicating low to moderate intensity of pain associated with routine orthodontic treatment. The most intense pain will be reported during mastication, and it remains at elevated levels [5]. Pain is a complex perceptual phenomenon and a subjective experience, its assessment is challenging. Pain can only be measured indirectly. The most common method for assessing orthodontic pain is the Visual Analogue Scale (VAS). This method is designed to present the respondent with a rating scale, with minimum constraints. The respondent marks a location on the $100 \mathrm{~mm}$ line corresponding to the experienced pain level from 0 to 100 [6]. The mechanism whereby the application of orthodontic forces results in pain/ discomfort is not fully understood. Orthodontic tooth movement creates tension and compression zones in the densely innervated periodontal ligaments. Compression of the periodontal ligament will cause ischemia, and edema typical for activate inflammatory reaction with the presence of prostaglandins, substance $P$ and other substances being activated during tissue damage [7]. The present study focuses on relative patient behavior modification focusing on post orthodontic behavior assessment in relevance to pain management, eating behavior, influence on social activities and communication values

\section{Materials and Methods}

This study was conducted in the department of orthodontics at Karolinska institute, Huddinge, Stockholm. The study group comprised of 20 adolescent patients, from both sexes who were treated with fixed orthodontic appliances. Specific selfadministered log-books covering aspects of pain sensation, oral hygiene, eating habits, sleep, speech and social activities. Data were collected, coded and analyzed by descriptive statistics. This study was approved by the regional ethical review board of Stockholm (Nr 2012/1082-31/1).

1. Participants were subjected to the following inclusion criteria:

a. To be healthy adolescents, ages range between 12-18 years

b. To be treated by residents in orthodontic clinic at Karolinska Institute, Huddinge c. No history of previous experience with fixed orthodontic treatment.

2. Appliances were subjected to the following inclusion criteria:

a. Fixed orthodontic appliances only

b. Placed in one or both dental arches.

The data collected included 40 specific diary log-books in Swedish language were designed and prepared to be distributed to the participants. Log-books include the following:

a. Usage instructions page.

b. First registration period that designed to be filled first week on daily bases: $\left(1^{\text {st }}, 2^{\text {nd }}, 3^{\text {rd }}, 4^{\text {th }}, 5^{\text {th }}, 6^{\text {th }}\right.$ and $7^{\text {th }}$ day)

c. Second registration period that designed to be filled on weekly bases: $\left(2^{\text {nd }}, 3^{\text {rd }}, 4^{\text {th }}, 5^{\text {th }}, 6^{\text {th }}, 7^{\text {th }}\right.$

and $8^{\text {th }}$ week).

Each page contains two parts to be answered.

a. Pain sensation degree when / when not biting and chewing.

b. Duration and nature of pain, pain management measures

c. Presence of soft tissues ulcerations and any desire to cease treatment

d. Effect of appliances on eating habits, speech and social activities

e. Effect of appliances on sleep and oral hygiene habits

f. Benefits gained from pretreatment information

g. Any lack or missing pretreatment information

Answer modes: VAS scale, Likert scale, and free answer.

The patients included in the study were managed by few guidelines in order to remove the bias as well as to maintain the stable results. These included:

a. At the treatment plan visit, or at the day of appliance installation, patients were asked to participate.

b. Patients were instructed how to use the log-books immediately after appliance installation.

c. Patients were asked to return the log-book to the resident after completion

d. The selection was random and restricted to patients meet inclusion criteria

e. Only patients who completed their log-books as instructed and retuned it back were accepted. Partially answered log-books were rejected.

Forty patients participated in the study among which 20 patients completed their log-books as instructed. Data was collected and coded. In this descriptive study, results are expressed as mean values and percentages. SPSS software version 22 was used for statistical analysis. 


\section{Results}

For the pain experience it was documented that $80 \%$ could manage to continue the treatment without pain by the end of the first week, while $20 \%$ were still having mild to moderate pain (2-6 on the VAS), except in one patient who experienced severe pain (9 on VAS) during the $5^{\text {th }}$ week. Figures 1-4 show marked decrease in pain intensity with time.

By the end of the first period only $20 \%$ had used pain killers. Cheek and tongue ulcerations were reported by $50 \%$ of participants on the $1^{\text {st }}$ day of the treatment, and that number has reduced to reach $35 \%$ by the end of the follow up period (= 8 weeks). Only one patient considered terminating treatment due to pain, and his treatment was terminated after $2^{\text {nd }}$ stage of the study. Tables $\mathbf{1}$ and $\mathbf{2}$ below shows patients answers to Q2-Q5.

\section{Individual registered pain degrees without biting (q1a) and with} biting (q1b) were shown below in Figures 5-12

It was found that $25 \%$ of the study sample passed the initial eight weeks of orthodontic treatment with fixed appliances without any negative impacts on their daily life activities (Tables 3 and 4). 25\% of patients reported impact on speech and social activities mainly during the $1^{\text {st }}$ week. Two patients reported sleep impairment that accompanied with social and speech impacts. Marked improvement in oral hygiene habits was reported by $80-90 \%$ of the participants (Tables 3 and 4). Pretreatment information was beneficial to the majority of the patients (95\%).

$20 \%$ of the patients commented on changing their food selection. Few patients were keen to answer the last question completely,

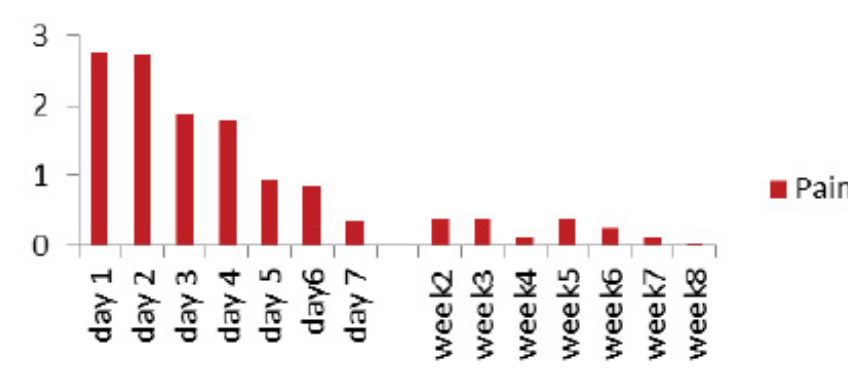

Figure 1 Mean pain values according to VAS without biting.

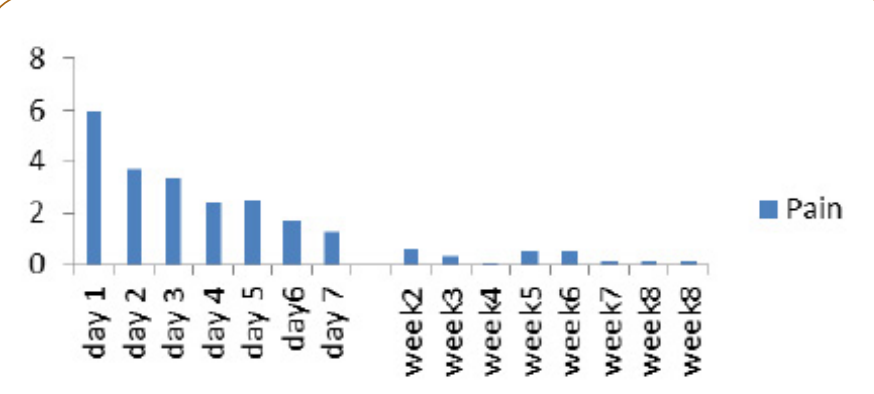

Figure 2 Mean pain values according to VAS wit biting. and that question was about any lack or missing pretreatment information was faced by the patient. Patient A: "On the third day, he started asking for how long he will be having the appliances?" Patient O: "He was in a severe pain for the first 5 days, and then he stopped therapy later on. Patients $\mathrm{K}, \mathrm{M}$ : "Their concern was on the termination of favorite food items such as hard food" Patients B, C, G, and I: "They had speaking and social problems during first five days only. Patients $D, F, Q, S$, and $T$ : "No negative impacts from the start until the end".

\section{Discussion}

The pain in the first week of having the appliances was experienced by $80 \%$ of participants, and it was relieved and eliminated by the end of that period [4,8]. Pringle et al. [9] proposed that selfadaptation could justify this high percentage of pain tolerance. On the other hand $20 \%$ of the sample had an extended period of pain after the first week, the pain degrees were ranging between 2-6 in VAS scale, and that extended pain referred to individual tolerance or inadequate patient preparation and support. In this study patient individuality was obvious, a good example of that was the patient with most painful experience. His pain sensation continued until the $5^{\text {th }}$ week with severe pain level (=9 degrees) on VAS scale, and as a consequence to that, the patient requested to discontinue the treatment. This individual experience confirms what was reported by Pringle about pain to be the key reason for a wish to stop orthodontic treatment. Jawad et al. [4] proposed in their study that, pain sensation during the first week when biting and chewing was experienced by $40 \%$ of the participants, which could be the reason why the patients have changed their

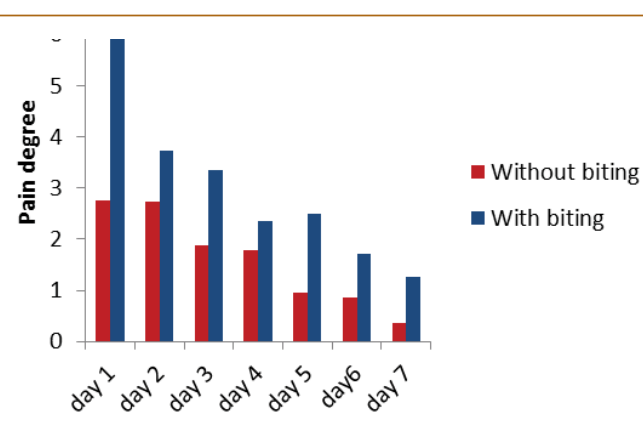

Figure 3 Mean pain values according to VAS in stage 1 .

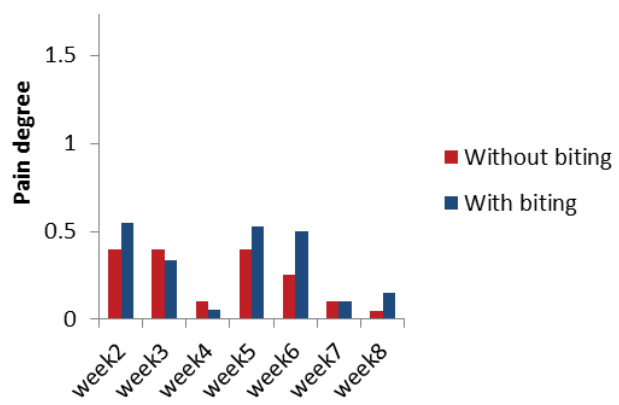

Figure 4 Mean pain values according to VAS in stage 2 . 
eating habits and shifted to softer food. That change presented in $20 \%$ of the study sample, and could be considered healthy and positive who found positive changes of dietary behavior with all patients as a response to pain, and instructions given to by their orthodontist. But on the other hand a study conducted by Benson et al. [10] disagrees with instructions to stop chewing and he found that chewing gum reduced the pain accompanied with fixed appliances without any increase risk of appliances breakage. He recommended patients to chew gum whenever it suits them. This means that this issue is controversial. In a study conducted by Fleming et al. [11], twenty percent of the participants were using pain killers by the end of the 1st week. Pain killer usage should be among the orthodontist routine instructions and advice to the patients after installation of the appliances. More than $60 \%$ of adolescent patients have used analgesics to relief the pain

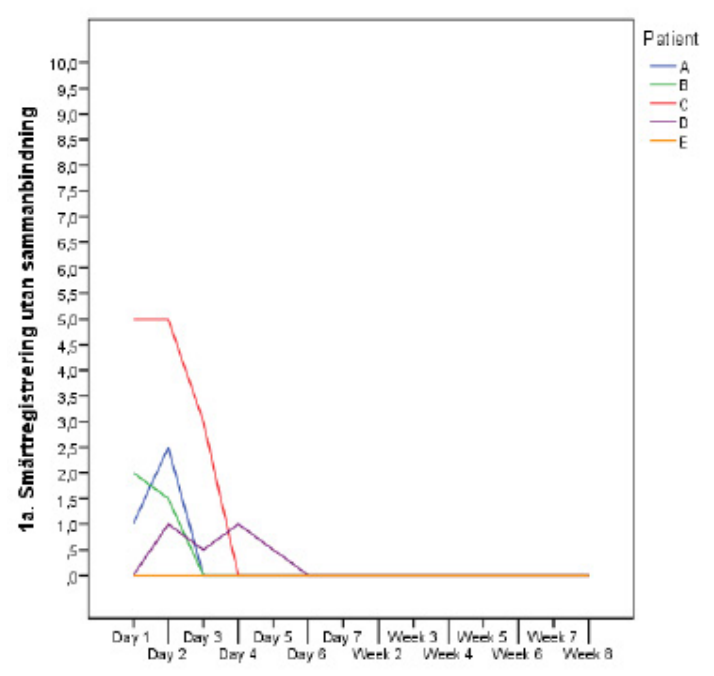

Figure 5 Group 1 q1a. of the first week. Otasevic et al. [12] reported that, during the first three days after appliance placement most of the analgesics were taken. The cheek and tongue ulcerations were reported by $50 \%$ of participants during the 1st day of the treatment, and this is expected and not a major clinical problem. The appliances design can be the cause, and that can be managed by providing the patient with wax, and by careful orthodontist handling to the appliances. It was reported to be the second most frequently problem which caused complain to $42 \%$ of the subjects. Sergl et al. [8] has proposed that, twenty-five percent of patients experienced speech and social handicap mainly during the 1st week and that problem can be due to having the appliance in the mouth for the first time which may cause pronunciation difficulties, also patients may feel that appliance is traumatic so they develop avoidance approach. Since the adolescence age is

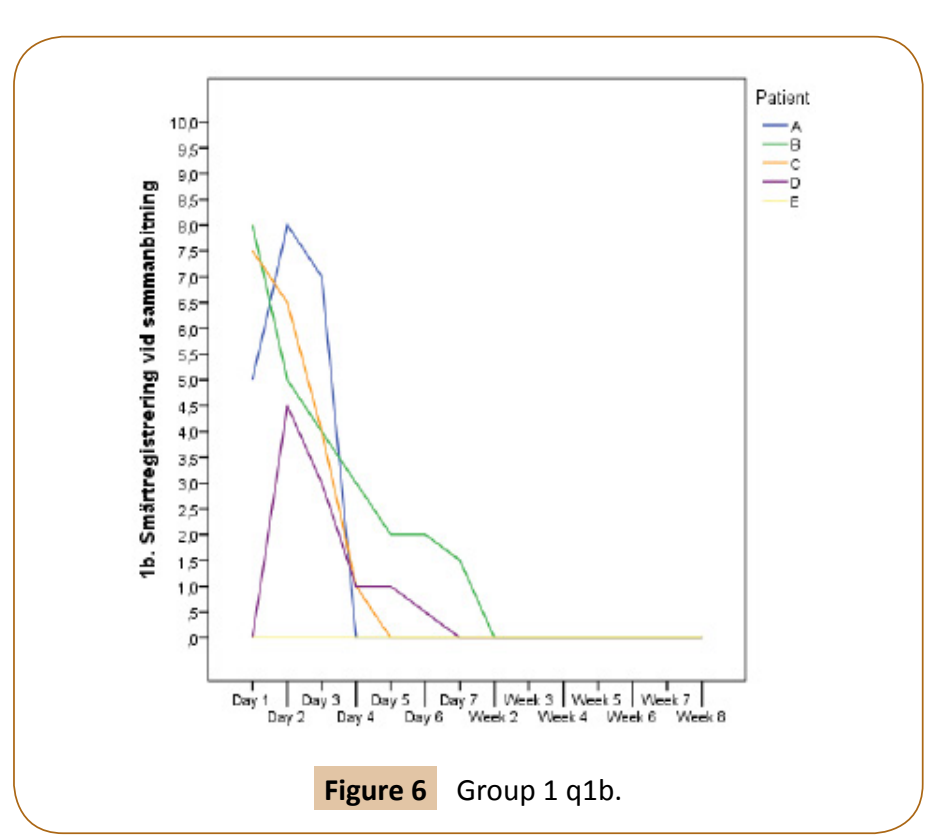

Table 1: Answers to Q 2-5 in stage 1. Each patient $=5 \%$.

\begin{tabular}{|c|c|c|c|c|c|c|c|c|}
\hline Questions & Answers & Day 1 (\%) & Day 2 (\%) & Day $3(\%)$ & Day $4(\%)$ & Day 5 (\%) & Day 6 (\%) & Day 7 (\%) \\
\hline \multirow{5}{*}{ 1. If you have pain? Does it hurt? } & No pain & 20 & 15 & 15 & 20 & 20 & 25 & 35 \\
\hline & All time & 25 & 30 & 20 & 15 & 5 & 0 & 0 \\
\hline & Only when chewing & 10 & 10 & 10 & 15 & 10 & 10 & 10 \\
\hline & Only when biting & 10 & 0 & 15 & 15 & 25 & 35 & 30 \\
\hline & $\begin{array}{l}\text { Both biting and } \\
\text { chewing }\end{array}$ & 35 & 45 & 40 & 35 & 40 & 30 & 25 \\
\hline \multirow{2}{*}{$\begin{array}{l}\text { 2. what has been used to relieve } \\
\text { the pain? }\end{array}$} & Nothing & 45 & 35 & 65 & 60 & 75 & 80 & 80 \\
\hline & Painkiller & 55 & 65 & 35 & 40 & 25 & 20 & 20 \\
\hline \multirow{2}{*}{$\begin{array}{l}\text { 3. do you have sore throat and } \\
\text { any difficulty in the swallowing } \\
\text { and the tongue }\end{array}$} & No & 50 & 40 & 45 & 40 & 50 & 65 & 70 \\
\hline & Yes & 50 & 60 & 55 & 60 & 50 & 35 & 30 \\
\hline \multirow{2}{*}{$\begin{array}{l}\text { 4. have to thought of } \\
\text { discontinuing treatment because } \\
\text { of pain }\end{array}$} & No & 100 & 100 & 100 & 100 & 100 & 95 & 95 \\
\hline & Yes & 0 & 0 & 0 & 0 & 0 & 5 & 5 \\
\hline
\end{tabular}


Table 2 Answers to Q 2-5 in stage 2. Each patient $=5 \%$.

\begin{tabular}{|c|c|c|c|c|c|c|c|c|}
\hline Questions & Answers & $\begin{array}{c}\text { Week } 2 \\
\text { (\%) }\end{array}$ & Week 3 (\%) & Week 4 (\%) & Week 5 (\%) & Week 6 (\%) & Week 7 (\%) & Week 8 (\%) \\
\hline \multirow{5}{*}{$\begin{array}{l}\text { 7. If you have pain does } \\
\text { it hurts? }\end{array}$} & No pain & 50 & 55 & 65 & 75 & 70 & 70 & 75 \\
\hline & All time & 0 & 5 & 5 & 5 & 5 & 0 & 0 \\
\hline & Only when chewing & 10 & 10 & 10 & 0 & 5 & 10 & 0 \\
\hline & Only when biting & 25 & 10 & 20 & 20 & 15 & 15 & 15 \\
\hline & $\begin{array}{l}\text { Both biting and } \\
\text { chewing }\end{array}$ & 15 & 20 & 0 & 0 & 5 & 5 & 10 \\
\hline \multirow{2}{*}{$\begin{array}{l}\text { 8. What did you do to } \\
\text { relieve the pain? }\end{array}$} & Nothing & 90 & 95 & 100 & 90 & 95 & 95 & 95 \\
\hline & Pain killer & 10 & 5 & 0 & 10 & 5 & 5 & 5 \\
\hline \multirow{2}{*}{$\begin{array}{l}\text { 9. Do you have sore } \\
\text { throats, cheeks and } \\
\text { gums? }\end{array}$} & No & 60 & 70 & 65 & 60 & 60 & 70 & 65 \\
\hline & Yes & 40 & 30 & 35 & 40 & 40 & 30 & 35 \\
\hline \multirow{2}{*}{$\begin{array}{l}\text { 10. have to thought of } \\
\text { discontinuing treatment } \\
\text { because of pain? }\end{array}$} & No & 100 & 100 & 100 & 100 & 100 & 100 & 95 \\
\hline & Yes & 0 & 0 & 0 & 0 & 0 & 0 & 5 \\
\hline
\end{tabular}

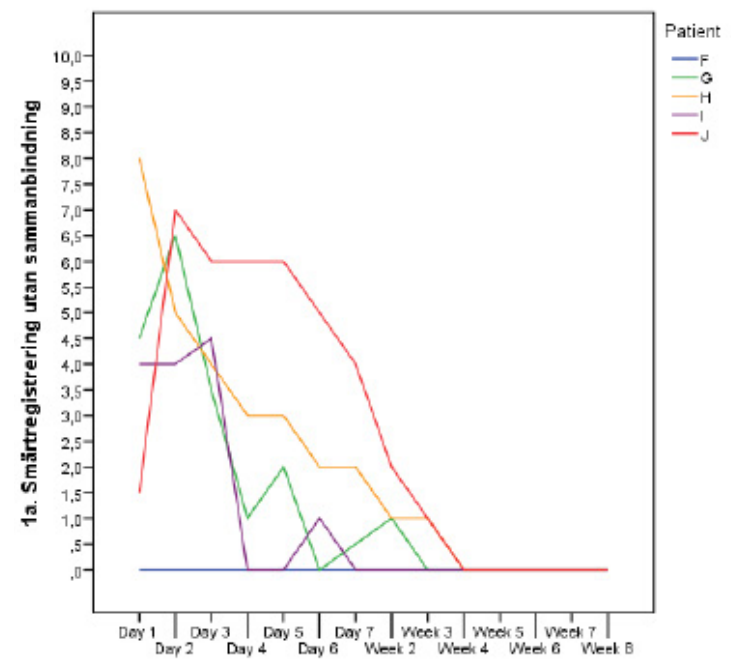

Figure 7 Group2 q1a.

full of social events and activities, some patients tend to reduce such activities as a consequence of their impaired speech and smiling habits which resulted from their feeling the appliance either looks funny, scary or feels uncomfortable. Impacts of wearing fixed appliances on speech and swallowing. The study by Bernabe et al. [13] shows a negative impact on sleep and was reported in $10 \%$ of the studied patients, which was accompanied with social and speech impairment and didn't exceed the first week. No specific reason was detected and that could be related to pain or patient future concern. This negative impact is rarely mentioned in the literature and indicated that activities such as maintaining emotional stability or relaxing including sleeping were not usually affected. In a relevant study by Oliver and Knapman [14] proposed that, pre-treatment information

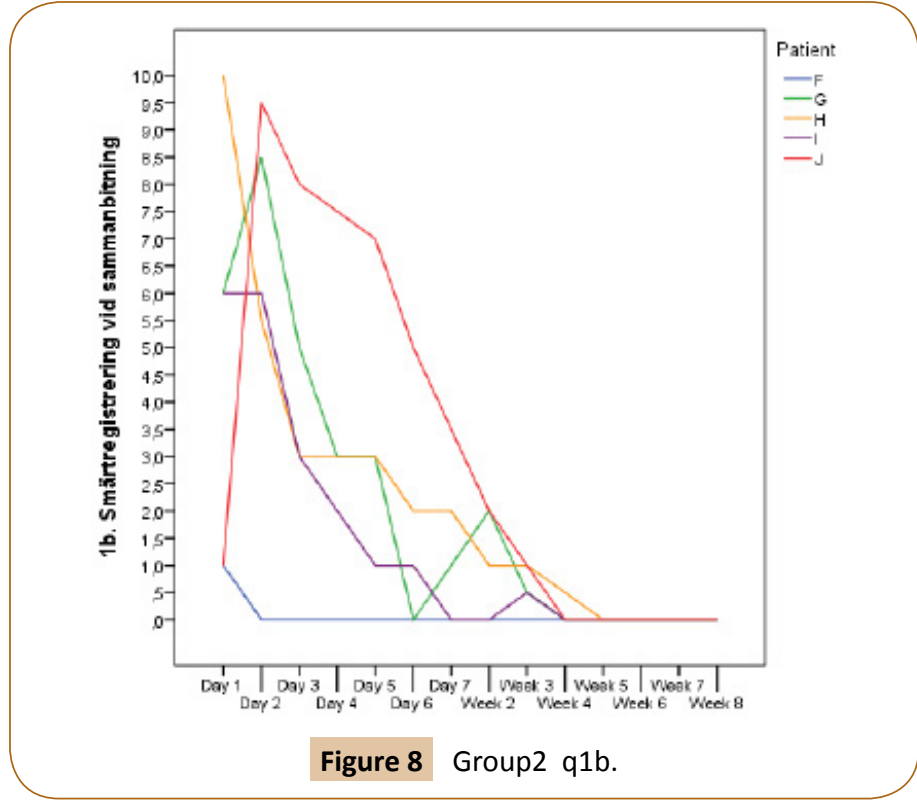

was beneficial for the great majority of the study sample, which is to be considered as a successful result. The quality of information given and patient preparation done before start the treatment is reflected directly on the experience will be passed by the patient. Many essential factors in this regard should be considered among which comes the orthodontist's skills in delivering clear, consistent, understandable information, and the ability to build a proper communication channel with the patient and parent. Content of the pretreatment information is a very important factor too, and should be comprehensive and precise. Daniela et al. [15] proposed that, inadequate information; poor orthodontist-patient communication or relation will end up in poor results and suboptimal treatment experience and have reported that many people were exposed to inadequate 


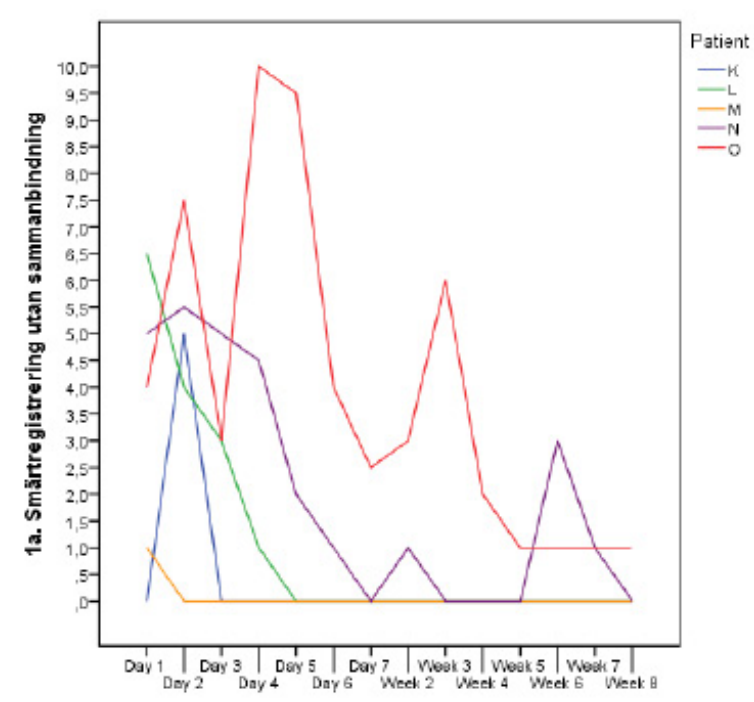

Figure 9 Group3 q1a.

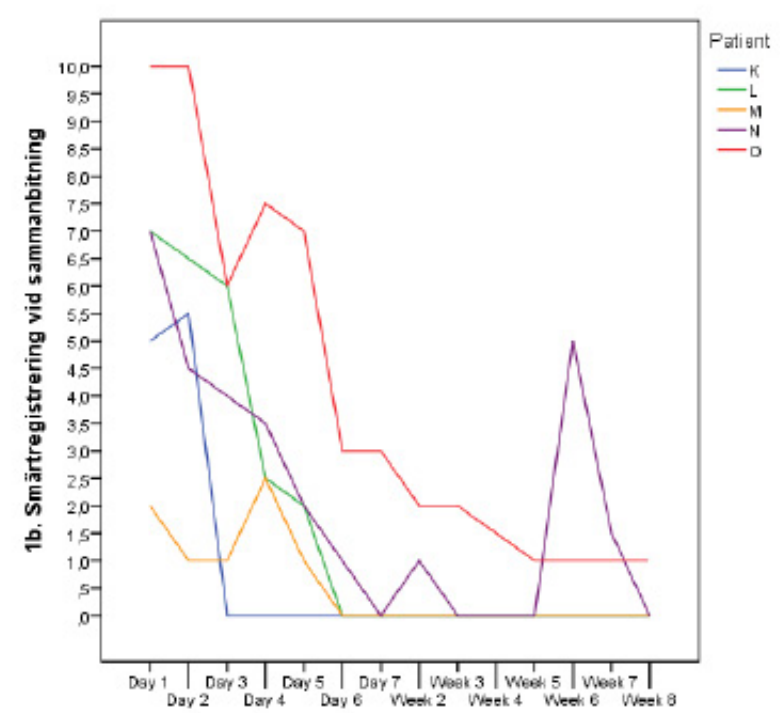

Figure 10 Group3 q1b.

information. Treatment continuity is at risk if the orthodontist fails to communicate properly with the patient in early stages. In a study by Zhang et al. [16] they reported that, clear understanding of patient's expectations of treatment can help inform "informed consent" as well as help patients to develop coping strategies to deal with treatment sequels. Chen et al. [1] also suggested that doctors need to provide more guidelines to patients at week one about the daily impact. That in turn will be beneficial in helping patients overcome the negative effect of therapy and enhance their belief and confidence in their doctor. Bernabe et al. [13] suggested that Psychosocial life aspects of orthodontic patient should be highly considered by the treating orthodontist prior to treatment, the most common social impacts on daily living should be discussed with potential patients before they given
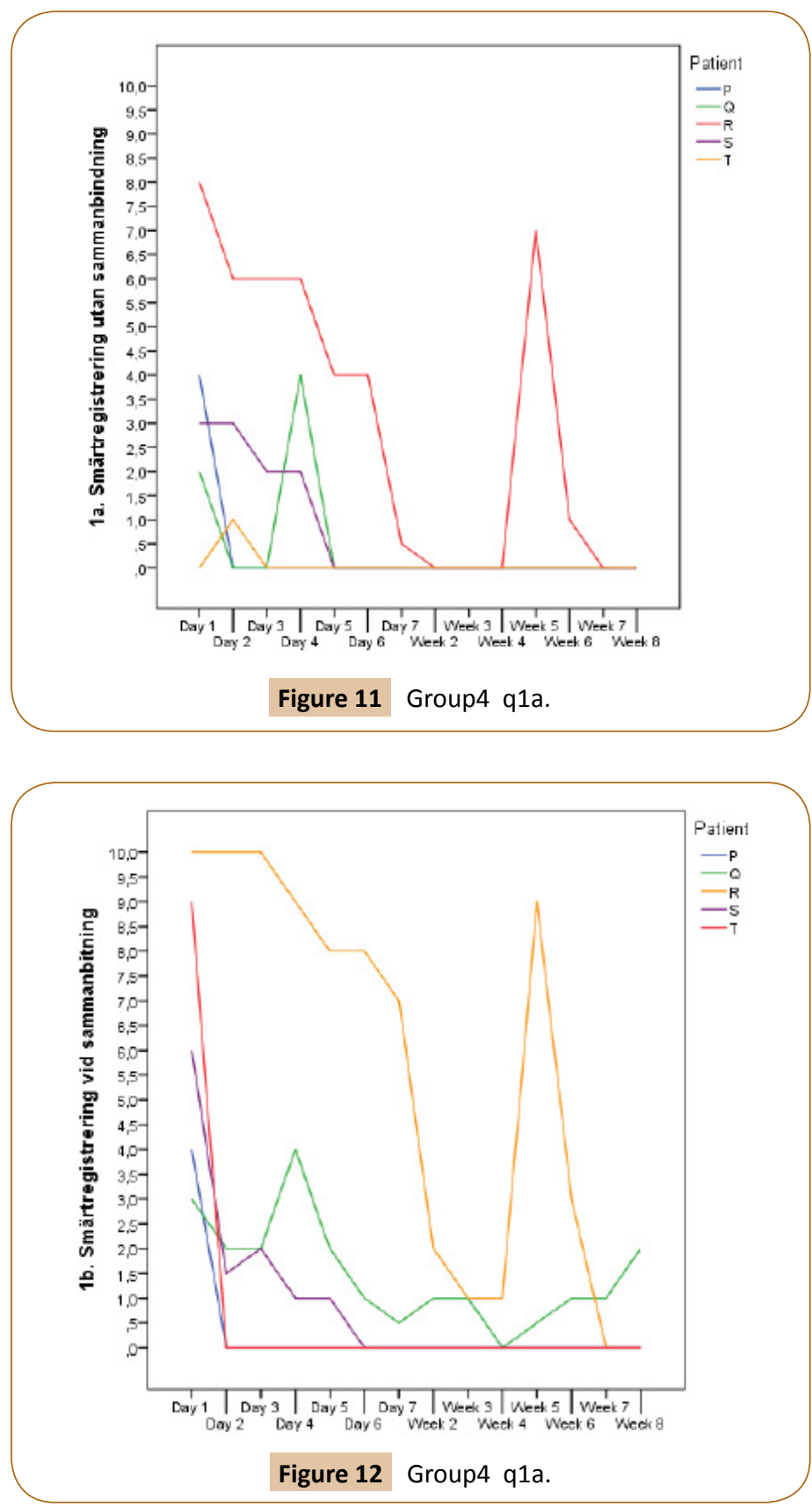

informed consent to treatment. Only $15 \%$ of participants were keen to answer last question completely. This could be justified by the following reasons:

1. Satisfaction with the information given to them.

2. The question is open ended, and patients felt they have nothing to add.

3. It is the last question, which is usually neglected by respondents.

Small sample size and short observational period were the main limitations to this study, the explanation for that is summarized below:

1. Small study sample, only 20 patients, and that due to 
Table 3 Answers to Q 7-11 in stage 1 . Each patient $=5 \%$.

\begin{tabular}{|c|c|c|c|c|c|c|c|c|}
\hline Questions & Answers & Day 1 (\%) & Day $2(\%)$ & Day 3 (\%) & Day 4 (\%) & Day 5 (\%) & Day 6 (\%) & $\begin{array}{l}\text { Day } \\
7(\%)\end{array}$ \\
\hline \multirow{4}{*}{$\begin{array}{l}\text { 7. Do you think the toothpick } \\
\text { affects your speech? }\end{array}$} & That is correct & 10 & 5 & 5 & 5 & 0 & 0 & 0 \\
\hline & Feels pretty good & 5 & 20 & 20 & 15 & 20 & 5 & 5 \\
\hline & To a certain extent & 25 & 20 & 25 & 25 & 15 & 30 & 30 \\
\hline & Not correct at all & 60 & 55 & 50 & 55 & 65 & 65 & 65 \\
\hline \multirow{4}{*}{$\begin{array}{l}\text { 8. Do you think the } \\
\text { toothpaste affects the leisure } \\
\text { activities? intercourse and }\end{array}$} & That is correct & 15 & 15 & 10 & 10 & 5 & 5 & 10 \\
\hline & Feels pretty good & 0 & 10 & 5 & 5 & 5 & 5 & 0 \\
\hline & To a certain extent & 20 & 20 & 25 & 25 & 20 & 15 & 15 \\
\hline & Not correct at all & 65 & 55 & 60 & 60 & 70 & 75 & 75 \\
\hline \multirow{4}{*}{$\begin{array}{l}\text { 9. Do you think the } \\
\text { toothpaste affects your sleep? }\end{array}$} & That is correct & 10 & 15 & 5 & 10 & 0 & 0 & 5 \\
\hline & Feels pretty good & 15 & 15 & 10 & 10 & 10 & 5 & 0 \\
\hline & To a certain extent & 10 & 5 & 20 & 5 & 10 & 10 & 5 \\
\hline & Not correct at all & 65 & 65 & 65 & 75 & 80 & 85 & 90 \\
\hline \multirow{4}{*}{$\begin{array}{l}\text { 10. Do you brush your teeth } \\
\text { more often than before you } \\
\text { had a toothpick? }\end{array}$} & That is correct & 40 & 25 & 30 & 25 & 20 & 25 & 35 \\
\hline & Feels pretty good & 35 & 40 & 35 & 40 & 40 & 35 & 25 \\
\hline & To a certain extent & 20 & 20 & 20 & 25 & 30 & 30 & 30 \\
\hline & Not correct at all & 5 & 15 & 15 & 10 & 10 & 10 & 10 \\
\hline \multirow{4}{*}{$\begin{array}{l}\text { 11. How is the information } \\
\text { you received before } \\
\text { treatment consistent with } \\
\text { how you experienced the } \\
\text { treatment? }\end{array}$} & That is correct & 60 & 55 & 45 & 50 & 65 & 60 & 65 \\
\hline & Feels pretty good & 35 & 35 & 45 & 45 & 30 & 30 & 30 \\
\hline & To a certain extent & 5 & 5 & 5 & 5 & 5 & 10 & 5 \\
\hline & Not correct at all & 0 & 5 & 5 & 0 & 0 & 0 & 0 \\
\hline
\end{tabular}

inability to distribute all the 50 planned and prepared logbooks completely, in addition to having 50\% drop out in the 40 distributed log-books. Several reasons could justify that, such as the big difference between the residents capability to follow up the patients, adolescents avoidance to participate in such studies that contains log-books because they may consider it as additional homework.

2. The short observation period. Our initial plan was to run the study in three stages in total period of 6 months, but that was modified to be consisted of two stages with total period of 2 months, the reason was to increase the motivation to participate, and to reduce the withdrawal risk expected with studies that extend for long periods.

The age group of the participants could be the main reason for this big drop out since the awareness level in adolescence period is questionable, and the probability to refuse the participation or neglecting the log-book after participation is high. The study result could have been influenced by the size of the sample, but that did not prevent the presence of variation and diversity in the individual experiences.

\section{Conclusion}

The impact of orthodontic treatment with fixed appliances on the daily life activities of adolescents are expected to occur, mainly during the first week of treatment, primarily because of pain and discomfort. Those impacts can be controlled and managed by good communication between patient and doctor. Adding the social and speech impacts part in the treatment consent could be recommended. 
Table 4 Answers to $Q 7-11$ in stage 2 . Each patient $=5 \%$.

\begin{tabular}{|c|c|c|c|c|c|c|c|c|}
\hline Questions & Answers & $\begin{array}{c}\text { Week } 2 \\
\text { (\%) }\end{array}$ & $\begin{array}{c}\text { Week } 3 \\
(\%)\end{array}$ & $\begin{array}{c}\text { Week } 4 \\
\text { (\%) }\end{array}$ & $\begin{array}{c}\text { Week } 5 \\
\text { (\%) }\end{array}$ & $\begin{array}{c}\text { Week } 6 \\
(\%)\end{array}$ & $\begin{array}{c}\text { Week } 7 \\
(\%)\end{array}$ & $\begin{array}{c}\text { Week } 8 \\
(\%)\end{array}$ \\
\hline \multirow{4}{*}{$\begin{array}{l}\text { 12. Do you think the toothpick affects } \\
\text { your speech? }\end{array}$} & That is correct & 5 & 0 & 0 & 0 & 0 & 0 & 0 \\
\hline & Feels pretty good & 10 & 5 & 0 & 5 & 5 & 5 & 0 \\
\hline & To a certain extent & 25 & 20 & 30 & 15 & 25 & 20 & 20 \\
\hline & Not correct at all & 60 & 75 & 70 & 80 & 70 & 75 & 80 \\
\hline \multirow{4}{*}{$\begin{array}{l}\text { 13. Do you think the leisure activities? } \\
\text { toothpaste affects the intercourse and }\end{array}$} & That is correct & 10 & 10 & 5 & 5 & 0 & 0 & 0 \\
\hline & Feels pretty good & 5 & 5 & 0 & 5 & 5 & 5 & 10 \\
\hline & To a certain extent & 15 & 5 & 10 & 5 & 15 & 15 & 10 \\
\hline & Not correct at all & 70 & 85 & 85 & 85 & 80 & 80 & 80 \\
\hline \multirow{4}{*}{$\begin{array}{l}\text { 14. Do you think the toothpaste affects } \\
\text { your sleep? }\end{array}$} & That is correct & 5 & 5 & 0 & 0 & 0 & 0 & 0 \\
\hline & Feels pretty good & 0 & 5 & 0 & 0 & 5 & 0 & 0 \\
\hline & To a certain extent & 5 & 0 & 10 & 10 & 0 & 5 & 5 \\
\hline & Not correct at all & 90 & 90 & 90 & 90 & 95 & 95 & 95 \\
\hline \multirow{4}{*}{$\begin{array}{l}\text { 15. Do you brush your teeth more often } \\
\text { than before you had a toothpick? }\end{array}$} & That is correct & 35 & 25 & 25 & 20 & 30 & 25 & 30 \\
\hline & Feels pretty good & 25 & 30 & 35 & 35 & 30 & 30 & 25 \\
\hline & To a certain extent & 30 & 35 & 25 & 35 & 25 & 30 & 35 \\
\hline & Not correct at all & 10 & 15 & 15 & 10 & 15 & 15 & 10 \\
\hline \multirow{4}{*}{$\begin{array}{l}\text { 16. How is the information you received } \\
\text { before treatment consistent with how } \\
\text { you experienced the treatment? }\end{array}$} & That is correct & 75 & 70 & 65 & 65 & 70 & 70 & 70 \\
\hline & Feels pretty good & 20 & 25 & 30 & 15 & 20 & 25 & 25 \\
\hline & To a certain extent & 5 & 5 & 5 & 15 & 10 & 5 & 5 \\
\hline & Not correct at all & 0 & 0 & 0 & 5 & 0 & 0 & 0 \\
\hline
\end{tabular}

\section{References}

Chen M, Wang DW, Wu LP (2010) Fixed orthodontic appliance therapy and its impact on oral health-related quality of life in Chinese patients. Angle Orthod 80: 49-53.

2 Tecco S, D'Attilio M, Tetè S, Festa $F$ (2009) Prevalence and type of pain during conventional and self-ligating orthodontic treatment. Eur J Orthod 31: 380-384.

Scheurer PA, Firestone AR, Burgin WB (1996) Perception of pain as a result of orthodontic treatment with fixed appliances. Eur J Orthod 18: 349-357.

4 Abed Al JF, Cunningham SJ, Croft N, Johal A (2012) A qualitative study of the early effects of fixed orthodontic treatment on dietary intake and behavior in adolescent patients. Eur J Orthod 34: 432-436.

5 Salmassian R, Oesterle L, Shellhart WC, Newman SM (2009) Comparison of the efficacy of ibuprofen and acetaminophen in controlling pain after orthodontic tooth movement. Am J Orthod Dentofac Orthop 135: 516-521.

6 Krishnan V (2007) Orthodontic pain: from causes to management -- a review. Eur J Orthod 29: 170-179.

Burstone C (1964) Biomechanics of tooth movement. In: Vistas in Orthodontics (Kraus BS, Riedel RA Edn). Lea and Febiger, Philadelphia, pp: 197-213.
Sergl HG, Klages U, Zentner A (1998) Pain and discomfort during orthodontic treatment: causative factors and effects on compliance. Am J Orthod Dentofac Orthop 14: 684-691.

9 Pringle AM, Petrie A, Cunningham SJ, McKnight M (2009) Prospective randomized clinical trial to compare pain levels associated with 2 orthodontic fixed bracket systems. Am J Orthod Dentofac Orthop 136: $160-167$.

10 Pringle AM, Petrie A, Cunningham SJ, McKnight M (2009) Prospective randomized clinical trial to compare pain levels associated with 2 orthodontic fixed bracket systems. Am J Orthod Dentofac Orthop 136: $160-167$.

11 Fleming PS, Dibiase AT, Sarri G, Lee RT (2009) Pain experience during initial alignment with a self-ligating and a conventional fixed orthodontic appliance system. A randomized controlled clinical trial. Angle Orthod 79: 46-50.

12 Otasevic M, Naini FB, Gill DS, Lee RT (2006) Prospective randomized clinical trial comparing the effects of a masticatory bite wafer and avoidance of hard food on pain associated with initial orthodontic tooth movement. Am J Orthod Dentofac Orthop 130: 9-15.

13 Bernabe E, Sheiham A, de Oliveira CM (2008) Impacts on daily performances related to wearing orthodontic appliances. Angle Orthod 78: 482-486.

14 Oliver RG, Knapman YM (1985) Attitudes to orthodontic treatment. Br J Orthod 12: 179-188. 
15 Daniela F (2011) Why orthodontists should be aware of the quality of life of their patients. Dent Press J Orthod 1: 13-16.
16 Zhang M, McGrath C, Hägg U (2007) Patients' expectations and experiences of fixed orthodontic appliance therapy. Impact on quality of life. Angle Orthod 77: 318-322. 